\title{
How to Increase Users' Social Commerce Engagement? A Technology Attractiveness Model
}

\author{
Xiao-Liang Shen \\ Economics and Management \\ School, Wuhan University \\ xlshen@whu.edu.cn \\ Zhen-Jiao Chen \\ School of Management and \\ Economics, Beijing Institute of \\ Technology \\ sharon2009@bit.edu.cn
}

\author{
Yang-Jun Li \\ Economics and Management \\ School, Wuhan University \\ lyon@whu.edu.cn \\ Kem Z.K. Zhang \\ School of Management, \\ University of Science and \\ Technology of China \\ zzkkem@ustc.edu.cn
}

\author{
Yongqiang Sun \\ School of Information \\ Management, Wuhan University \\ sunyq@whu.edu.cn
}

Sesia J. Zhao

School of Management,

Anhui University

sesia@ahu.edu.cn

\begin{abstract}
With the proliferation of social networking and electronic commerce, social commerce helps people engage in various forms of online social commercial activities through sharing their product or service knowledge and experiences. A better understanding of users' engagement in social commerce websites thus become increasingly important. Based on the attractiveness theory, this study proposes a research model that highlights the unique role of technology attractiveness, including task, social, and physical attractiveness, in promoting user involvement, which in turn affects social commerce engagement. Results demonstrate that users' perceptions of technology attractiveness are positively associated with their involvement with social commerce websites, and further stimulate engagement. In addition, website involvement partially and fully mediates the effects of social and physical attractiveness, respectively, on social commerce engagement. The limitations and implications of this study for research and practice are further discussed.
\end{abstract}

\section{Introduction}

Over the past decade, the explosive growth of ecommerce has made this market highly competitive. Therefore, some companies are starting to conduct commercial marketing activities in social networking sites (SNS) because online shoppers often make their purchase decisions based on the recommendations from their friends [1]. In this manner, the increasing popularity of SNS extends e-commerce to a new paradigm, called social commerce [2]. In social commerce, users can explore shopping opportunities and make informed purchases by engaging in online social interactions with their friends [1,3]. Although prior research provides ample evidence for the high potential of social commerce in generating significant revenue [2], social commerce business managers still encounter obstacles when implementing social commerce in practice. First, consumers' intention to engage in social commerce is relatively low, and they have even shown their disgust with too much social commercial activities, such as advertising and sales promotions, that often appear on social networking platforms [4]. Second, attracting and retaining new social commerce consumers becomes increasingly expensive due to considerably low switching costs [5]. According to a recent report by Korea Chamber of Commerce and Industry, after adopting social commerce strategies, profits of $50.3 \%$ of enterprises still remained at the original level and $6.0 \%$ even suffered profit decline because of the challenges as we discussed above. In this regard, identifying the underlying processes facilitating social commerce engagement is urgently important.

Prior studies have identified attractiveness as an important belief in information systems (IS) adoption and usage domain [5-7]. Attractiveness, derived from interpersonal relationship literature, is used to indicate one's tendency to positively evaluate another person, and an attractive person has more influence on human communication behavior [8, 9]. Recently, some studies have tried to understand the role of attractiveness in affecting users' online behavior, such as website usage and online interaction [5, 7]. However, further investigation is rarely available in the IS literature. More importantly, these studies primarily focused on limited aspects of attractiveness, 
but neglected the complexity and multidimensional nature of attractiveness. In this sense, this study intends to provide a more comprehensive framework of attractiveness based on the attractive theory, which is drawn from communication discipline [8, 9]. In addition, we integrate the concept of attractiveness with IS literature to make this study more valid and relevance.

A new construct, technology attractiveness, is proposed in this study and it incorporates the three dimensions of task, social and physical attractiveness $[8,9]$. Technology attractiveness is likely to exert significant effects on users' online behavior, and its impact on social commerce engagement still needs further exploration. In this paper, a technology attractiveness model will be developed to better understand the mechanism through which technology attractiveness affects customer engagement in social commerce context.

\section{Theoretical background}

\subsection{Social commerce and engagement}

In recent years, as an emerging paradigm of ecommerce, social commerce has received increased attention from both scholars and practitioners [3, 4]. However, social commerce has not yet been ambiguously defined. For example, Kozinets [10] noted that online interactions in virtual community of consumption were based on shared interest in a specific commercial or social-related activities, which was considered as the earliest form of social commerce. In a broad sense, Zhou [3] indicated that social commerce involved the use of Internet-based media that allowed users to participate in all life cycle of products or services in both online and offline marketplaces. Overall, we define social commerce as a business model that integrates socialmediated and commercial-mediated online interactions in promoting product and service transactions in social media context.

It is not hard to distinguish social commerce from traditional e-commerce. First, traditional e-commerce just focuses on transactions, and users will not engage in it if they do not want to purchase any products or services. However, social commerce focuses on building social connections, and users may participate to facilitate social interaction, other than solely for transactions [3]. Second, social commerce is commercial activities supported by social media, and users conduct commercial transactions mainly with the support of shared product information and recommendation from their online friends. In contrast, traditional e-commerce is technical-supported commercial activities, and users improve their efficiency of online transactions primarily with the instrumental assistance in systems, such as search engine and preference-based recommender systems [2]. In this regard, different from traditional e-commerce that highlights the role of technology, users' social commerce engagement is of great importance to social commerce success.

Generally, engagement means behavioral manifestation that represents users' willingness to invest time, attention, and energy into social commerce activities [11, 12]. The effect of user engagement on social commerce can be seen in both commercial and social outcomes. On one hand, user engagement is believed to enhance commercial transactions by increasing traffic to social commercial sites, exploring new businesses opportunities, and maximizing the efficiency of marketing campaigns [3], which enables social commercial businesses to obtain a better position to predict market trends [2, 3]. On the other hand, user engagement can also increase the reliability of business social interactions [3, 13]. Users' purchase decisions in social commerce are not only affected by information presented on websites, but also mainly rely on shared experience and recommendation from their online friends $[1,2]$, which strengthens business and social relationships with customers. In this regard, it is important to explore the factors affecting user's social commerce engagement.

\subsection{Attractiveness theory}

Attractiveness theory originally came from human communication literature and focused on the positive effects of interpersonal attraction on the effectiveness of real-world social interaction and communication [8, 9]. Interpersonal attraction concerns people's judgments about whether they like another person or feel good in that person's presence [8,9]. When people are attracted to another person, they tend to evaluate that person positively. McCroskey and McCain [9] conceptualized interpersonal attraction as task, social, and physical attraction. Particularly, task attraction refers to the possibility of other individuals helping to accomplish tasks. Social attraction is the extent of one person integrating in someone's social circle. Physical attraction is defined as the degree in which other person's physical attributes are regarded as handsome or beautiful.

According to attractiveness theory, interpersonal attraction exerts significant effects on social interaction, which will further affect human cognition and behavior. When a group is attractive to a person, 
that person will enjoy communicating with the group and identify with being part of this group (i.e., involvement) [14, 15]. This emotional involvement increases pro-social behavior in a group [16]. Following this line to social commerce, when task, sociability, and design aesthetics in SNS are attractive to users, it will promote users' involvement and social commerce engagement. This reasoning regarding the outcomes of attractiveness has been investigated separately in IS literature. Phang [17] determined that usability and sociability would indeed affect users' behavior in online communities. Usability refers to the capability of systems to fulfill users' tasks easily and effectively, which has been widely regarded as a key factor in IS adoption [2, 17]. Sociability means the capability of systems to support users' social interaction [17, 18]. With the rise of social interaction in IS, social usefulness gains more attention in IS adoption [17, 18]. In addition, Cyr [19] demonstrated that visual design aesthetics would influence users' loyalty in mobile services. In particular, visual design means that colors, shapes, font types, music, or animation in the website are appealing and aesthetical, which has been generally regarded as system quality $[1,18]$ and visual appeal $[20,21]$ in IS adoption.

In summary, IS literature has highlighted the importance of attraction in IS adoption from different aspects, but a systematic organization of such attraction is lacking. Because the three dimensions of interpersonal attraction have covered different aspects of system features noted above, this study develops a new integrated framework-technology attractiveness - based on attractiveness theory to capture the multidimensionality of attractiveness completely. More importantly, there exists relatively few theory-driven empirical research on the multidimensional nature of attractiveness in IS adoption and usage domain. In this regard, considering theoretical consistency with the vast body of IS adoption literature, the current study may provide a better understanding of IS adoption from a new integrated attractiveness framework.

\section{Research model and hypotheses}

Figure 1 shows the proposed research model based on attractiveness theory and arguments above.

\subsection{SNS involvement and social commerce engagement}

SNS involvement, derived from virtual community involvement that refers to "a state of motivation, arousal, or interest toward online community" [22], means that users enjoy participation in and feel identified with being part of SNS [16]. In prior studies, involvement has been widely linked to prosocial behavior, particularly user engagement in organizations or online platforms $[11,12,22]$. When people feel involved with a group, participating in group activities will be pleasurable and mean much to them [16], which will increase their various positive behavior, such as personal investment, participation, and paying attention in the group, that is, engagement in the context of this study [11]. In social commerce, it is thus predicted that, when more users feel involved with SNS, their desire to engage in social commerce activities should be stronger. Therefore, we propose that:

$\mathbf{H}_{1}$ : SNS involvement is positively associated with users' social commerce engagement.

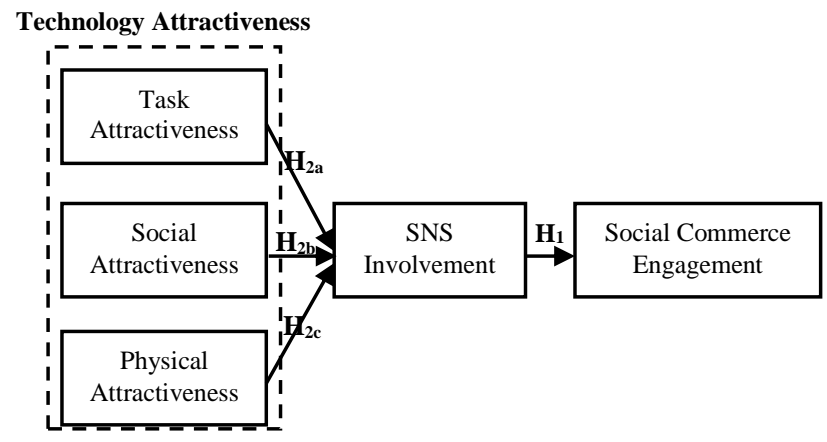

Figure 1. Research model

\subsection{Technology attractiveness and SNS involvement}

Technology attractiveness is conceptualized as three dimensions: task, social, and physical attractiveness based on attractiveness theory [8, 9]. As discussed in Section 2, task attractiveness means the attraction rooted in SNS ability in helping users to complete tasks [9, 14]. Users conduct social commerce activities mainly under the guidance of shared product information and recommendations from their friends on SNS [3]. In this regard, SNS offers users with advice, guidance, or useful information to help them make purchase decisions [3]. If people consistently gain valuable information guidance from SNS, they will be more inclined to recognize its value and adopt it, which is believed to invoke a feeling of identification with SNS [1, 2]. Task attractiveness thus increases users' perception of usefulness of SNS, which in turn increases their acceptance of being part of and feeling involved with SNS. Therefore, we propose that: 
$\mathbf{H}_{2 \mathbf{a}}$ : Task attractiveness in SNS is positively associated with users' SNS involvement.

Social attractiveness refers to the extent in which SNS effectively support social interaction among its users [8, 9]. When users are attracted to SNS sociability, they are likely to feel more comfortable to adopt it. The improved social interaction by SNS assists people in organizing their social practice, construing their identities and fostering intimate friendships both online and offline [17, 23]. In this regard, social attractiveness increases users' perception of social usefulness of SNS, which will allow them to perceive support (e.g., respect, recognition, approval, and so on) from their friends [17] and enable them to identify themselves as belonging to and feeling emotionally involved with SNS [2]. Therefore, we propose that:

$\mathbf{H}_{2 b}$ : Social attractiveness in SNS is positively associated with users' SNS involvement.

Physical attractiveness refers to the degree in which users believe the SNS design is visually pleasing [9]. In human communication and marketing literature, physically attractive people are more favorable on social and intellectual competence, and integrity [15]. Following this research line, SNS with design aesthetics is likely to better meet users' needs for social interaction, which will improve users' perception of its usefulness and win user favors [17, 19]. In addition, a well-designed website improves users' perception of enjoyment $[17,20]$, as well as the perceived ease of use [19]. In this regard, when SNS design is attractive to users, users are likely to receive a pleasurable experience of adopting it, which will further generate a sense of belongingness to and involvement with SNS. Therefore, we propose that:

$\mathbf{H}_{2 \mathbf{c}}$ : Physical attractiveness in SNS is positively associated with users' SNS involvement.

\subsection{The mediating effect of SNS involvement}

Together, hypotheses 1-2c suggest a chain of relationships linking technology attractiveness with SNS involvement, which is hypothesized to be positively related to social commerce engagement in turn. This mechanism implies that technology attractiveness has an indirect effect on users' social commerce engagement via their SNS involvement. In this regard, users' SNS involvement may be the key factor in promoting users' social commerce engagement because of technology attractiveness. In other words, users will first develop a feeling of involvement with SNS because of technology attractiveness and then intend to engage in social commercial activities. Therefore, the feeling of SNS involvement evoked by technology attractiveness is responsible for users' social commerce engagement. In this case, user involvement with SNS operates as a mediating mechanism between technology attractiveness and users' social commerce engagement. Therefore, we propose that:

$\mathbf{H}_{3 \mathbf{a}}$ : SNS involvement mediates the relationship between task attractiveness in SNS and users' social commerce engagement.

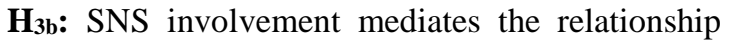
between social attractiveness in SNS and users' social commerce engagement.

$\mathbf{H}_{3 \mathbf{c}}$ : SNS involvement mediates the relationship between physical attractiveness in SNS and users' social commerce engagement.

\section{Research methodology}

In this study, the users of Douban.com (https://www.douban.com/) were chosen as the main target population in the online survey. As one of the most famous social commerce sites in Mainland China, Douban is built on specific interests and shared connections, which allows its users to create and share ratings and comments on thousands of books with their online friends. This is distinct from other transaction-oriented websites, such as Amazon and Taobao. Particularly, there are many hobby groups in Douban, and users are frequently engaged in group activities and taking advice from their online friends before they make actual purchase decisions. Therefore, Douban is a perfect social website to investigate social commercial activities.

The measurements of all the constructs in this study were adapted from English publications (see Appendix A); however, the survey was conducted in Mainland China. In this regard, the questionnaire was translated into Chinese first, and then a backward translation method was adopted to ensure the consistency between Chinese and original English questionnaires. Before initiating data collection, we interviewed some Douban users and experts in IS, and then conducted a pilot test to improve survey instruments. Their suggestions concerning the format and wordings of the questions were further incorporated in the revised questionnaire, where all measures were phrased on a seven-point Likert scale from 1 (strongly disagree) to 7 (strongly agree). Then, a link to the web-based questionnaire was sent to people who had a homepage on Douban. Finally, a total of 376 valid responses were obtained. The demographic characteristics of the respondents are presented in Table 1. 
Table 1. Demographic statistics $(\mathrm{N}=376)$

\begin{tabular}{|c|c|c|c|c|c|}
\hline Characteristics & Frequency & Percentage & Characteristics & Frequency & Percentage \\
\hline \multicolumn{3}{|l|}{ Age } & \multicolumn{3}{|l|}{ Gender } \\
\hline$\leq 25$ & 227 & 60.37 & Male & 178 & 47.34 \\
\hline 26-30 & 82 & 21.81 & Female & 198 & 52.66 \\
\hline$>30$ & 67 & 17.82 & \multicolumn{3}{|c|}{ Usage Experience with Douban } \\
\hline \multicolumn{3}{|l|}{ Education } & $\leq 12$ Months & 71 & 18.88 \\
\hline$\leq$ Junior College & 39 & 10.37 & 1-2 Years & 97 & 25.80 \\
\hline Undergraduate & 232 & 61.70 & 3-4 Years & 96 & 25.53 \\
\hline$\geq$ Postgraduate & 105 & 27.93 & $>4$ Years & 112 & 29.79 \\
\hline \multicolumn{3}{|c|}{$\begin{array}{l}\text { In the past } 3 \text { months, how many reviews you have } \\
\text { read from Douban Book? }\end{array}$} & \multicolumn{3}{|c|}{$\begin{array}{l}\text { In the past } 3 \text { months, how many reviews you have } \\
\text { posted on Douban Book? }\end{array}$} \\
\hline$\leq 10$ & 90 & 23.94 & $\leq 1$ & 171 & 45.48 \\
\hline $11-15$ & 84 & 22.34 & $2-3$ & 118 & 31.38 \\
\hline $16-30$ & 99 & 26.33 & $4-5$ & 38 & 10.11 \\
\hline$>30$ & 1.3 & 27.39 & $\geq 6$ & 49 & 13.03 \\
\hline
\end{tabular}

\section{Data analysis and results}

SmartPLS 2.0 was utilized to validate the proposed research model and test the significance of our hypotheses. Partial least squares (PLS) approach has been extensively applied in IS research, especially in the early stage of theory development [24], which consists the exploratory nature of this study. Following the two-step data analytical procedures, the measurement model was first examined to ensure the reliability and validity of measures, and then the structural model was tested to estimate the hypothesized relationships.

\subsection{Measurement model}

Composite reliability (CR), average variance extracted (AVE), Cronbach's $\alpha$ (CA), and loadings were evaluated first to assess the internal consistency and validity of the measurement model. As shown in Table 2, all measures exceed the recommended thresholds. In particular, CR ranges from 0.853 to 0.963, which is higher than 0.7, and CA ranges from 0.743 to 0.949 , which is higher than 0.7 ; thus, all constructs exhibit good internal reliability [24]. In addition, all AVEs range from 0.659 to 0.867 , which is higher than 0.5; and loadings are higher than 0.7, which demonstrates good convergent validity of all constructs [24].

The given construct's square root of AVE and its correlations with other constructs were compared to assess the discriminant validity of constructs. As shown in Table 3, all the given constructs' square roots of AVE are higher than the correlations with other constructs, which indicates that all of constructs exhibit good discriminant validity [24]. In addition, as shown in Table 2, all loadings on the intended construct are higher than loadings on other constructs, which demonstrates the satisfactory discriminant validity of the measurement [24].

\subsection{Structural model}

PLS results of the structural model analysis are depicted in Figure 2. Results illustrate that the exogenous variables explained $31.1 \%$ of the variance in social commerce engagement and $53.6 \%$ of the variance in SNS involvement. In addition, results demonstrate that SNS involvement exerts significant effect on social commerce engagement with path coefficient at 0.557, supporting $\mathbf{H}_{1}$. Furthermore, the three dimensions of technology attractiveness, that is, task, social, and physical attractiveness, are proven to pose significant effects on SNS involvement, with path coefficients at $0.084,0.615$, and 0.132 , respectively. Therefore, $\mathbf{H}_{2 \mathbf{a}}, \mathbf{H}_{\mathbf{2 b}}$, and $\mathbf{H}_{2 \mathrm{c}}$ are supported.

Mediation test was performed following the steps proposed by Zhao [25], who advanced Baron and Kenny's method [26], to further examine the mediating role of SNS involvement in the relationships between technology attractiveness and social commerce engagement. According to Zhao [25], if the corresponding indirect effect is significant, mediation will exist. In this respect, we particularly developed a new extended PLS model that included 
three direct paths between technology attractiveness and social commerce engagement, and results are presented in Figure 3. In addition, to estimate the significance of the three indirect effects in this extended model, we conducted the Sobel z-test. As presented in Table 4, results demonstrate that SNS involvement partially mediates the effect of social attractiveness, while fully mediating the effect of physical attractiveness on users' social commerce engagement, supporting $\mathbf{H}_{\mathbf{3}}$ and $\mathbf{H}_{\mathbf{3}}$. However, SNS involvement fails to mediate the effect of task attractiveness on social commerce engagement. Therefore, $\mathbf{H}_{\mathbf{3}}$ is not supported.

Table 2. Construct reliability and validity

\begin{tabular}{|c|c|c|c|c|c|c|c|c|c|}
\hline Constructs & $\mathrm{CR}$ & AVE & $\mathrm{CA}$ & Items & TAAT & SOAT & PHAT & SIN & SCEN \\
\hline \multirow{4}{*}{$\begin{array}{c}\text { Task } \\
\text { Attractiveness }\end{array}$} & \multirow{4}{*}{0.919} & \multirow{4}{*}{0.739} & \multirow{4}{*}{0.882} & TAAT1 & 0.804 & 0.367 & 0.402 & 0.368 & 0.445 \\
\hline & & & & TAAT2 & 0.878 & 0.421 & 0.448 & 0.408 & 0.382 \\
\hline & & & & TAAT3 & 0.897 & 0.428 & 0.465 & 0.369 & 0.402 \\
\hline & & & & TAAT4 & 0.856 & 0.480 & 0.453 & 0.420 & 0.432 \\
\hline \multirow{4}{*}{$\begin{array}{c}\text { Social } \\
\text { Attractiveness }\end{array}$} & \multirow{4}{*}{0.954} & \multirow{4}{*}{0.839} & \multirow{4}{*}{0.935} & SOAT1 & 0.469 & 0.942 & 0.410 & 0.690 & 0.507 \\
\hline & & & & SOAT2 & 0.430 & 0.950 & 0.405 & 0.671 & 0.540 \\
\hline & & & & SOAT3 & 0.449 & 0.935 & 0.374 & 0.674 & 0.547 \\
\hline & & & & SOAT4 & 0.474 & 0.833 & 0.405 & 0.573 & 0.545 \\
\hline \multirow{4}{*}{$\begin{array}{c}\text { Physical } \\
\text { Attractiveness }\end{array}$} & \multirow{4}{*}{0.955} & \multirow{4}{*}{0.843} & \multirow{4}{*}{0.938} & PHAT1 & 0.437 & 0.369 & 0.918 & 0.364 & 0.343 \\
\hline & & & & PHAT2 & 0.492 & 0.429 & 0.930 & 0.440 & 0.385 \\
\hline & & & & PHAT3 & 0.444 & 0.412 & 0.933 & 0.401 & 0.346 \\
\hline & & & & PHAT4 & 0.511 & 0.377 & 0.890 & 0.411 & 0.364 \\
\hline \multirow{4}{*}{$\begin{array}{c}\text { SNS } \\
\text { Involvement }\end{array}$} & \multirow{4}{*}{0.963} & \multirow{4}{*}{0.867} & \multirow{4}{*}{0.949} & SIN1 & 0.419 & 0.681 & 0.398 & 0.911 & 0.531 \\
\hline & & & & SIN2 & 0.419 & 0.649 & 0.395 & 0.950 & 0.524 \\
\hline & & & & SIN3 & 0.426 & 0.645 & 0.419 & 0.925 & 0.499 \\
\hline & & & & SIN4 & 0.437 & 0.681 & 0.434 & 0.937 & 0.520 \\
\hline \multirow{3}{*}{$\begin{array}{c}\text { Social } \\
\text { Commerce } \\
\text { Engagement }\end{array}$} & \multirow{3}{*}{0.853} & \multirow{3}{*}{0.659} & \multirow{3}{*}{0.743} & SCEN1 & 0.291 & 0.411 & 0.231 & 0.360 & 0.790 \\
\hline & & & & SCEN2 & 0.357 & 0.508 & 0.377 & 0.503 & 0.867 \\
\hline & & & & SCEN3 & 0.509 & 0.485 & 0.327 & 0.472 & 0.776 \\
\hline
\end{tabular}

Table 3. Descriptive statistics of the constructs

\begin{tabular}{c|c|c|c|c|c|c|c}
\hline & Mean & S.D & TAAT & SOAT & PHAT & SIN & SCEN \\
\hline TAAT & 4.584 & 1.231 & $\mathbf{0 . 8 6 0}$ & & & & \\
\hline SOAT & 4.705 & 1.318 & 0.495 & $\mathbf{0 . 9 1 6}$ & & & \\
\hline PHAT & 4.686 & 1.347 & 0.515 & 0.434 & $\mathbf{0 . 9 1 8}$ & & \\
\hline SIN & 4.547 & 1.457 & 0.457 & 0.714 & 0.442 & $\mathbf{0 . 9 3 1}$ & \\
\hline SCEN & 4.387 & 1.317 & 0.483 & 0.582 & 0.393 & 0.557 & $\mathbf{0 . 8 1 2}$ \\
\hline
\end{tabular}

Note: The bold numbers in the diagonal row are square roots of the AVE.

Table 4. Significance levels of the direct and indirect effects

\begin{tabular}{c|c|c|c}
\hline Paths & Indirect Effect & Direct Effect & Results \\
\hline TAAT $\rightarrow$ SIN $\rightarrow$ SCEN & $0.019^{\text {N.S }}$ & $0.211^{* * * *}$ & No \\
\hline SOAT $\rightarrow$ SIN $\rightarrow$ SCEN & $0.140^{* * *}$ & $0.292^{* * *}$ & Partially \\
\hline PHAT $\rightarrow$ SIN $\rightarrow$ SCEN & $0.030^{* * *}$ & $0.056^{\text {N.S }}$ & Fully \\
\hline
\end{tabular}

Note: ${ }^{*} p<0.1,{ }^{* *} p<0.05,{ }^{* * *} p<0.01$, N.S not significant. 


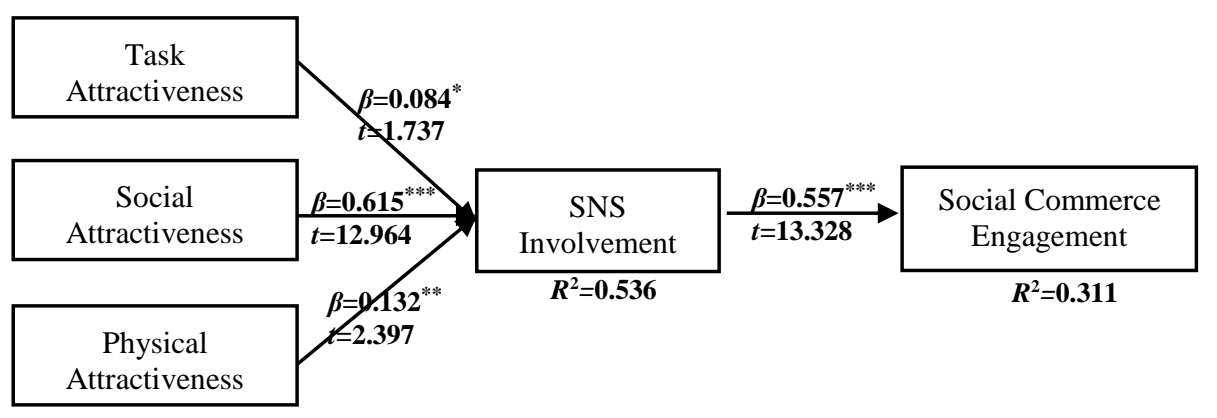

Note: ${ }^{*} p<0.1,{ }^{* *} p<0.05,{ }^{* * *} p<0.01$

Figure 2. PLS analysis results

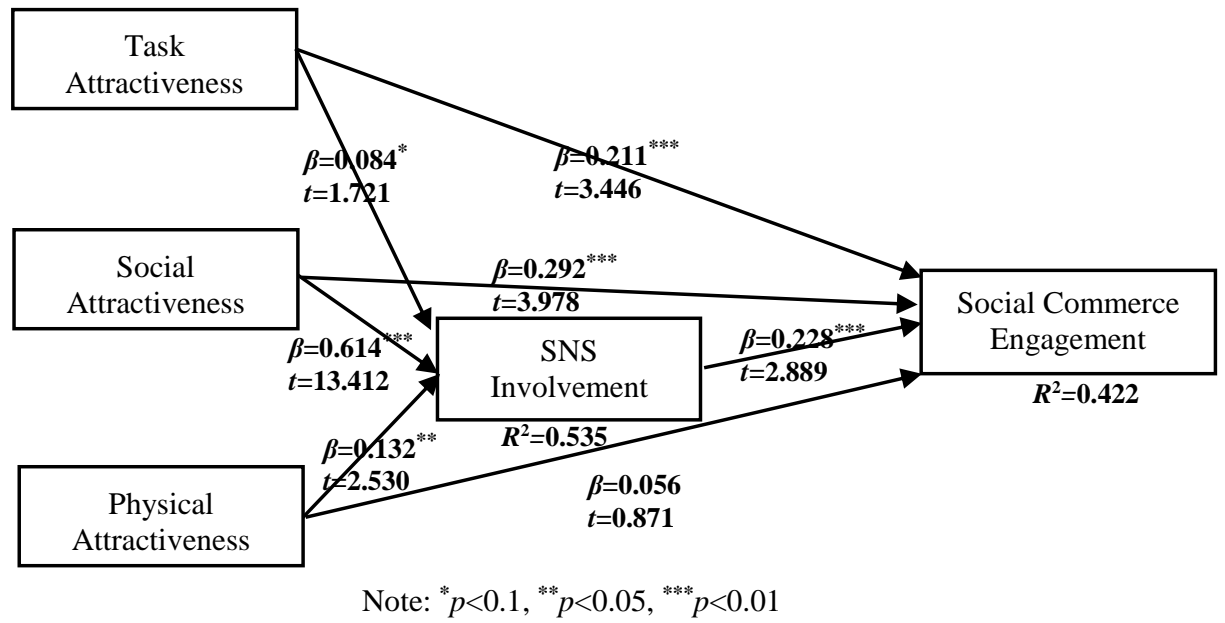

Figure 3. Structural model including direct paths

\section{Findings and discussion}

\subsection{Discussion of key findings}

This study highlights the role of technology attractiveness in promoting involvement and engagement. Findings after empirical examination reveal several interesting points as follows. First, this study explores customers' online behavior in social commerce context and further emphasizes the importance of engagement to social commerce success, particularly. Results suggest that users' involvement with SNS is positively associated with users' social commerce engagement, which is consistent with prior studies that demonstrate that users' involvement with online social platforms is likely to increase their engagement in activities in the said platforms [11, 12].

Second, this study indicates that task, social, and physical attractiveness are important determinants of users' involvement with SNS. Generally, these findings strongly support the idea that technology attractiveness is important in facilitating users' involvement with SNS. Results also offer additional insights for understanding how system features and designs contribute to users' involvement and engagement creation $[17,19]$.

Third, this study demonstrates the different mediating effects of SNS involvement exerting on the relationships between technology attractiveness and engagement. Specifically, SNS involvement partially mediates the effects of social attractiveness, while fully mediating the effects of physical attractiveness on social commerce engagement. However, involvement fails to mediate the effects of task attractiveness on user engagement. These findings imply that task attractiveness affects user engagement directly, whereas social and physical attractiveness indirectly influence user engagement via involvement with SNS. When users are attracted to information in social platforms that can help them complete a task, they will focus on this instrumental assistance and engage in platform activities that are needed, such as reading comments and sharing their own experiences, to get useful guidance directly [1]. In this case, users 
do not necessarily need to be emotionally involved with the social platform. In addition, when users are attracted to the sociability of SNS, they will pay more attention to the social interactions with their friends on SNS, which will promote their social commerce engagement. Moreover, improved social interactions are bound to facilitate users' involvement with the social platform [19], which is likely to increase user engagement in turn. Social attractiveness thus can affect user engagement both directly and indirectly, mediated by involvement. However, when users are attracted to the design aesthetics of SNS, they will participate even without a specific purpose because they feel involved with SNS, resulting from the attractive designs. In this case, users' involvement with the platform is believed to be the deep-rooted reason why users engage in social commerce because of physical attractiveness.

\subsection{Limitations and future research}

Despite yielding some interesting and original findings, several limitations of this study should be acknowledged before presenting the theoretical and practical implications. First, this study mainly aims to explore how technology attractiveness promotes user involvement and engagement on SNS. Therefore, this study only conceptualizes engagement as a first-order construct. However, engagement has been regarded as a multidimensional variable in the context of online social platforms [11, 12]. Future research should extend this research line, and further explore the relationships between technology attractiveness and multidimensions of engagement to improve the understanding of users' online behavior in social media.

Second, technology attractiveness of SNS has explained $53.6 \%$ of the variance in users' involvement with SNS. Thus, the three dimensions of technology attractiveness are important in understanding users' involvement with social platforms. However, to keep the model simple and controllable, some other important variables, such as relation quality and personal traits, are omitted in this study. In this regard, we recommend scholars to integrate these powerful ideas to further investigate factors affecting users' involvement and social commerce engagement.

Finally, since the online survey was conducted in Mainland China, the single culture may limit the applicability and generalizability of our findings in this study. Therefore, this potential issue provides an opportunity for future studies to extend this study across different national cultures.

\subsection{Theoretical implications}

The contributions of the study can be understood in the following ways. First, this study enriches the literature on social commerce by providing a research model concerning user engagement. Social commerce primarily relies on users' shared experiences, information, and recommendations. In this regard, users' active engagement in social commercial activities is the basis for social commerce success. In this study, we have presented an initial attempt to explore the influencing factors of users' social commerce engagement, and the exogenous variables explain $31.1 \%$ of the variance in engagement. Therefore, this study will improve our understanding of this emerging social-related phenomenon, and evoke academic investigations on the underlying mechanisms of users' decisionmaking in social web.

Second, this study has highlighted the role of technology attractiveness in promoting users' involvement and social commerce engagement. In general, systems' features, and designs were believed to increase users' pro-social behavior in social platforms. However, systematic work on investigating users' online behavior in social platforms from attractiveness perspective is limited. Motivated by this observation and consideration, we identified three dimensions of attractiveness of social platforms, that is, task, social, and physical attractiveness, based on attractiveness theory. Moreover, results indicate that these three dimensions of technology attractiveness of SNS have explained $53.6 \%$ of the variance in users' involvement with SNS, which will facilitate users' engagement in social commercial activities in turn. In this regard, technology attractiveness provides a new theoretical basis for future research on users' involvement and engagement creation in IS adoption.

Third, this study further indicates that users' involvement with SNS have different mediating roles in the relationships between technology attractiveness and social commerce engagement. More specifically, involvement partially mediates the effects of social attractiveness of SNS, while fully mediating the effects of physical attractiveness on users' social commerce engagement. However, involvement does not pose mediating effects on the relationship between task attractiveness and user engagement. These findings illustrate the different mechanisms through which technology attractiveness affects user engagement via involvement with social platforms. In this sense, this study may further contribute to advance the theoretical understanding on influencing mechanisms of technology attractiveness on 
engagement and offer a unique contribution to research on users' online behavior in social platforms.

\subsection{Practical implications}

This study also offers some valuable suggestions for social commercial practitioners. Since user engagement in social commercial activities is important in fueling the success of social commerce business, business managers should make maximum efforts to attract customers to engage in social commercial activities, such as sharing, commenting, or recommending information of products and services in social platforms. Furthermore, this study demonstrates that users' involvement with SNS will exert a positive effect on engagement. In the regard, business managers should work to increase users' sense of identification with SNS.

In terms of specific operations, this study has highlighted the role of technology attractiveness in promoting users' involvement and social commerce engagement. Particularly, users' involvement with social platforms fails to mediate the effects of task attractiveness on social commerce engagement, which implies that task attractiveness influences users' engagement in social commercial activities more directly. In this regard, in the stage of user requirement analysis in design of social commercial platforms, business managers should pay more attention to identifying potential customers' information needs. In addition, three dimensions of technology attractiveness are proven to be associated with users' involvement with SNS, and social attractiveness matters most, particularly. In this regard, in addition to task attractiveness, managers should pay attention to the sociability and aesthetics of social platforms, especially for sociability.

\section{Acknowledgement}

The work described in this paper was supported by the National Natural Science Foundation of China (Project No. 71671132, 71301125).

\section{Appendix A. Constructs and items}

\section{Task Attractiveness [19, 21]}

The comments on Douban are pretty much what I need to carry out my tasks.

The Douban adequately meets my information needs.

The Douban enhanced my effectiveness in finding suitable books.
The Douban made the task I want to accomplish easier to get done.

Social Attractiveness [17, 27]

It is conductive to interact with other members through the Douban.

It is easy to interact with other members through the Douban.

The Douban helps me to form warm relationships with other members.

The Douban gives me the opportunity to recommend ideas to other members.

\section{Physical Attractiveness [19, 21]}

The design (i.e., colors, boxes, menus, etc.) of the Douban is attractive.

The Douban looks professionally designed.

The overall look and feel of the Douban is visually appealing.

The Douban is visually pleasing.

\section{SNS Involvement [16]}

Participating in Douban is one of the most enjoyable things I do.

Participating in Douban is important to me.

Participating in Douban is pleasurable to me.

Participating in Douban means a lot to me.

\section{Social Commerce Engagement [28]}

I am engaged in writing reviews in Douban.

I often participate in online activities in Douban.

I frequently read book comments in Douban.

\section{References}

[1] T.P. Liang, Y.T. Ho, Y.W. Li, E. Turban, "What Drives Social Commerce: The Role of Social Support and Relationship Quality," International Journal of Electronic Commerce, vol. 16, pp. 69-90, 2011.

[2] J. Chen, X.L. Shen, "Consumers' Decisions in Social Commerce Context: An Empirical Investigation," Decision Support Systems, vol. 79, pp. 55-64, 2015.

[3] L. Zhou, P. Zhang, H.D. Zimmermann, "Social Commerce Research: An Integrated View," Electronic Commerce Research and Applications, vol. 12, pp. 61-68, 2013.

[4] L. Chen, R. Wang, "Trust Development and Transfer from Electronic Commerce to Social Commerce: An Empirical Investigation," American Journal of Industrial and Business Management, vol. 6, pp. 568576, 2016

[5] D.E. Campbell, J.D. Wells, J.S. Valacich, "Breaking the Ice in B2C Relationships: Understanding PreAdoption E-Commerce Attraction," Information Systems Research, vol. 24, pp. 219-238, 2013.

[6] R. Simeon, "Evaluating the Projection of Corporate Culture Online," International Business \& Economics Research Journal, vol. 9, pp. 79-94, 2010.

[7] D.T. Wilson, "An Integrated Model of Buyer-Seller Relationships," Journal of the Academy of Marketing Science, vol. 23, pp. 335-345, 1995. 
[8] L.L. McCroskey, J.C. McCroskey, V.P. Richmond, "Analysis and Improvement of the Measurement of Interpersonal Attraction and Homophily," Communication Quarterly, vol. 54, pp. 1-31, 2006.

[9] J.C. McCroskey, T.A. McCain, "The Measurement of Interpersonal Attraction," presented at the Western Speech Communication Association Convention, Hawaii, 1972.

[10] R.V. Kozinets, "E-tribalized marketing? The Strategic Implications of Virtual Communities of Consumption," European Management Journal, vol. 17, pp. 252-264, 1999.

[11] C. Cheung, M. Lee, X. Jin, "Customer Engagement in an Online Social Platform: A Conceptual Model and Scale Development," Presented at the 32nd International Conference on Information Systems, Shanghai, 2011.

[12] L.D. Hollebeek, "Demystifying Customer Brand Engagement: Exploring the Loyalty Nexus," Journal of Marketing Management, vol. 27, pp. 785-807, 2011.

[13] Z. Huang, M. Benyoucef, "From E-Commerce to Social Commerce: A Close Look at Design Features," Electronic Commerce Research and Applications, vol. 12, pp. 246-259, 2013.

[14] C. Ellegaard, "Interpersonal Attraction in BuyerSupplier Relationships: A Cyclical Model Rooted in Social Psychology," Industrial Marketing Management, vol. 41, pp. 1219-1227, 2012.

[15] B.D. Till, M. Busler, "The Match-Up Hypothesis: Physical Attractiveness, Expertise, and the Role of Fit on Brand Attitude, Purchase Intent and Brand Beliefs," Journal of Advertising, vol. 29, pp. 1-13, 2000.

[16] H.W. Kim, H.C. Chan, A. Kankanhalli, "What Motivates People to Purchase Digital Items on Virtual Community Websites? The Desire for Online Self-Presentation," Information Systems Research, vol. 23, pp. 1232-1245, 2012.

[17] C.W. Phang, A. Kankanhalli, R. Sabherwal, "Usability and Sociability in Online Communities: A Comparative Study of Knowledge Seeking and Contribution," Journal of the Association for Information Systems, vol. 10, pp. 721-747, 2009.

[18] X. Li, "Factors Influencing the Willingness to Contribute Information to Online Communities," New Media \& Society, vol. 13, pp. 279-296, 2011.

[19] D. Cyr, M. Head, A. Ivanov, "Design Aesthetics Leading to M-Loyalty in Mobile Commerce," Information \& Management, vol. 43, pp. 950-963, 2006.

[20] D.V. Parboteeah, J.S. Valacich, J.D. Wells, "The Influence of Website Characteristics on a Consumer's Urge to Buy Impulsively," Information Systems Research, vol. 20, pp. 60-78, 2009.

[21] E.T. Loiacono, R.T. Watson, D.L. Goodhue, "WebQual: An Instrument for Consumer Evaluation of Web Sites," International Journal of Electronic Commerce, vol. 11, pp.51-87, 2007.

[22] U.M. Dholakia, R.P. Bagozzi, "Motivational Antecedents, Constituents and Consequents of Virtual
Community Identity, Virtual and Collaborative Teams: Process, Technologies, and Practice," Springer, pp. 252-267, 2003.

[23] W. Bouman, B. de Bruin, T. Hoogenboom, A. Huizing, R. Jansen, M. Schoondorp, "The Realm of Sociality: Notes on the Design of Social Software," Presented at the 28th International Conference on Information Systems, Montreal, 2007.

[24] C. Fornell, F.L. Bookstein, "Two Structural Equation Models: LISREL and PLS Applied to Consumer Exit-Voice Theory," Journal of Marketing Research, vol. 19, pp. 440-452, 1982.

[25] X. Zhao, J.G. Lynch, Q. Chen, "Reconsidering Baron and Kenny: Myths and Truths about Mediation Analysis," Journal of Consumer Research, vol. 37, pp. 197-206, 2010.

[26] R.M. Baron, D.A. Kenny, "The Moderator-Mediator Variable Distinction in Social Psychological Research: Conceptual, Strategic, and Statistical Considerations," Journal of Personality and Social Psychology, vol. 51, pp. 1173-1182, 1986.

[27] R.M. Baron, D.A. Kenny, "The Moderator-Mediator Variable Distinction in Social Psychological Research: Conceptual, Strategic, and Statistical Considerations," Journal of Personality and Social Psychology, vol. 51, pp. 1173-1182, 1986.

[28] C.F.M. de Leon, T.A. Glass, L.F. Berkman, "Social Engagement and Disability in a Community Population of Older Adults the New Haven EPESE," American Journal of Epidemiology, vol. 157, pp. 633-642, 2003. 